\title{
Subject of Sexuality in a Contemporary Disciplinary Society: What We Learn from M. Foulcault and J. Butler about Ourselves*
}

\author{
Philipp Tagirov \\ Department of Social Philosophy \\ Peoples' Friendship University of Russia \\ 6 Miklukho-Maklaya Street \\ Moscow, Russia \\ E-mail: tagirov_fv@rudn.university
}

\begin{abstract}
The thesis about "the repressed sexuality" is opposed by the theory of discoursive and disciplinary control elaborated by $M$. Foucault and enhanced by a number of authors, including J. Butler. In the present article the authors study the essential claims of this theory and offer an analysis of what happens, in accordance with it, to the subject of sexuality in the contemporary society. Is the sexuality an object of suppression or its instrument? Does sexuality precede the disciplinary power or is it formed by it? Is there such thing as sexuality or are there multiple sexualities? How does the process of subjection produce the subject vulnerable to the effects of power and its abuse?
\end{abstract}

Keywords-control; discourse; gender; identity; power; sexuality; subject; M. Foucault; J. Butler

\section{INTRODUCTION}

M. Foucault's concept of a disciplinary society belongs to non-classical theories of power. Later thinkers who reflect on the mechanisms of discursive and symbolic control either try hard to "forget Foucault", as J. Baudrillard, or, criticizing and enhancing the certain details in his reasoning, as does $\mathbf{J}$. Butler, follow him and seem to perform as his almost direct heirs. What Foucault writes about power and sexuality is generally correlated (to some extent) with any time. However, Foucault's phenomenon could not have taken place not only in the era of the Aristotelian "Politics" or Machiavellian "The Prince", "Leviathan" or even "Capital", but also in times, for example, of W. Reich. His theory is the result of a new understanding that has become possible in a changed society. But also, this is a theory understanding the changed society.

\section{CONTROL AND DISCOURSIVE MECHANISMS OF SUBJECTION}

Foucault is skeptical about the "repressive hypothesis" formulated primarily in the papers by Z. Freud, W. Reich and $\mathrm{H}$. Marcuse and notes that pleasure and power do not

* The publication has been prepared with the support of the "RUDN University Program 5-100". abolish one another, they do not oppose each other, they follow each other and strengthen each other [1]. Sexuality is not so much suppressed as it is controlled, and with it, and through it, the individual is controlled [2]. If suppression of sexuality (which is inherent in one way or another to any social order) takes place, then certainly not its cushioning, as many supporters of the repressive hypothesis state: even in the strictest puritanical Victorian era, Foucault asserted, people did not talk about anything else as much as about sexuality. However, "speaking" is not a manifestation of freedom or even a mere by-product or sublimation of repressed sexuality. On the contrary, it is through constant pronouncing, continuous attraction of attention, and mental concentration on sexuality the so-called "putting into discourse", in which the individual speaks and interprets himself and his sexuality, is being produced.

Apart from the fact that, according to Foucault, power itself enjoys the pursuit of forbidden pleasures, the inclusion of Eros in the economy of power is also evident in mechanisms shaping the pleasure of a subject and the very possibility of this pleasure.

In contrast, for example, to Reich, which, according to Foucault, remains a prisoner of the existing discourse, Foucault understands sexuality not in the singular (as something inherent in all people) but in the plural sense - as sexualities. Formation of the subject in the context of a certain discourse is always the formation of a particular kind of his sexuality.

According to the theories of disciplinary-discursive control, power is not simply applied to the subject of sexuality, power also forms it. The individual subjectifies by becoming a subject to whom the relations of power are applied and who applies them himself according to the logic established by the existing discourse. In fact, what an individual is before his being subjected by the discourse of power is extremely difficult to say. He can obtain his subjectness only due to the fact that some external authority (power) provides the conditions for his existence as a subject and forms the trajectory of his desire. Giving birth to a 
subject of sexuality, the subjection, as Butler shows, makes him dependent on the discourse that he did not choose [3].

The identity of the individual, based on which he can solely demand his liberation (as a liberation of his particular self), is impossible without subjection, that is any demand for freedom and any action against power initially determined by its own mechanisms. Identity of minorities fighting for their rights, respectively, is also produced by the power that suppresses them.

The main type of identity through which an individual is aware of his subjectivity in the field of Eros is, of course, gender identity. While for Foucault gender is one of the examples of how the power forms the subject, from Butler's point of view, gender is the basis of power relations, which logic is already incorporated into the gender binarity. Traditionally, gender is considered to be a category derived from sex, since sex is biological, and gender is a set of social roles and expectations that are prescribed by a society to its members of a particular gender [4]. However, according to Butler, the very understanding of sex is gender-determined, because even our definition of biological differences between men and women is culturally and, consequently, gender-related, therefore not gender is a category secondary to sex, but on the contrary [5].

The social mechanisms that govern desire of a subject, according to Butler, are produced in accordance with the existing gender norm, which in itself is hardly conceptualized, but precedes any meaningful practices. The status of the norm, as Butler understands it, is similar in general to the status of the Law in J. Lacan. Gender manifests as a principle of the distribution of pleasure and power, and a deviation from the gender norm is presupposed by it and, as a rule, doesn't liberate from it, but only helps to activate the practices of normalization and, as a result, strengthens the reality of the norm [6].

Following the logic of Freud and Reich, Butler recognizes that the mechanisms of subordination of an individual to power are being incorporated in us from infancy, and the main conductor here is love. The child feels a passionate attachment towards his parents, however, this love can in no way be called free, because a child simply cannot help but love the parents on whom he depends wholly, whatever they are. It is thanks to the parents that the formation of the subjectivity of a child begins, but his love for them stands in the way of acquiring his own ego. One's subjectness cannot simply be a continuation of the subjectivity of another, even passionately loved, it demands a differentiation from the other, negation of the other, loss of the other. In the process of developing one's personality, the individual has to resist his own desire, therefore any subject produced by an authoritative discourse already carries the structure of power relations within himself in the form of a contradiction between desire and the need to suppress this desire for the sake of preserving his subjectness. The subject who addresses himself (his desire) in this model looks like a condition for the continuation of his existence [7]. Recalling that one of the key concepts of critical social theory is the category of "alienation" (K. Marx, H. Marcuse, E. Fromm), and the liberation of the individual is thought to be directly dependent on overcoming this alienation, let us ask ourselves how much, in such an understanding of the subjectivity that Butler suggests, an unaligned subject is really possible, if being a subject means being immanently estranged from oneself?

The impossibility of one's own desire, lack, deficiency, therefore, underlies the subjectivity. This principle of limitation, estrangement from the object of love, exclusion from desired relations, rooted in the mind of the individual and reproducing itself again and again, is the original basis for the subjection to power. As a child grows up, all mechanisms of power will be built on that principle, possible due to the logic of binary opposition [8]. Any individual structure of the representation of subjectness is inevitably based on this principle of exclusion (self and similar ones from others, since the subject is produced in a situation from which he excludes), and, therefore, always reproduce the logic of power relations.

The internal mechanism of self-control is designed so that the subject is not only inclined to obey the authorities, when the latter directly address him, but also carries a readiness to fulfill the imperious demands even before they are formulated. In this regard, Butler refers to the concept of "interpellation" by Louis Althusser and his example, in which an indefinite hail of a policeman, "Hey you!" will make passersby turn around, as they think, what if the authority figure addresses exactly them. Butler also notes that not only identity works for the system of control, but also the mechanisms of disidentification, "rejected identification", when the power does not seem to notice you, does not recognize your identity, cause the individual to join the logic of power in order to achieve recognition [9].

\section{DIFFUSING POWER}

Society, where power is exercised, first of all, in the form of disciplinary control, can be defined as a disciplinary society. As liberal-democratic principles are progressively asserted, the society of late capitalism assigns less control to the political institutions and concentrate on economic mechanisms working on the principle of "stimulus-reward". At the same time, the diffuse nature of the disciplinary power, as we see, doesn't dismantle the relatively stabilized classic power institutions - the larger the forms of power manifestation, the less dynamic they are and the more abstract their "power", but this should not feed our illusions about their role in the issue of controlling the subject.

Power, according to the theory of disciplinary control, is not simply the power of institutionalized repression, the source of which could be localized in a particular social group, class, or specific authority. The effects of power suppression and resistance - permeate, according to Foucault, all social relations [10]. Power is extended to personal, private types of experience of the subject (which are perceived by man as his own, while in fact, are the of structures of individual's participation in his own subjection) [11]. 
The institute of family, as Foucault claims, historically is influenced by two discourses: discourse of marriage (matrimony) and discourse about sexuality. The connection between these two discourses weakens at the beginning of the 20th century, however, according to Foucault, the Freudian discovery of the structure of family relations in the core of sexuality (the Oedipus complex) strengthens the relationship between matrimony and sexuality and at the same time strengthens the discourse of marriage itself [12]. The family itself acted and does act not as an institution that establishes a ban on sexuality, but, on the contrary, as the main agent of sexualization. In a disciplinary society, the family (or another educating institution that replaces the family) translates into its own space the main normalizing discourse which influences the parents.

\section{SCIENTIA SEXUALIS AND THE BEGINNING OF THE NORMALIZING SOCIETY}

Two key points in the history of the multiplication of control methods, as Foucault believes, are the practices of confession, established in the sixteenth century and having replaced the practices of voluntary repentance, and the medicalization of the discourse of sexuality that occurred in the early nineteenth century [13]. The raise of the discursively-disciplinary power itself, according to Foucault's research, can be dated the 18 th -20 th centuries.

In the late 18th - early 19th centuries the category of "flesh" is displaced by category of "organism", which allows desire and pleasure to become objects of no longer clerical, but secular "scientifically grounded" regulation (first medical, and then psychiatric).

Before the 18th century the discoursive attention is paid almost exclusively to marital space, the rest of sexuality is rarely taken into account. Since the 18th century family space finds itself in the zone of weak discursive attention, and discourse (a lot of discourses) focuses on numerous phenomena that are marginal to marital sexuality. The appeal to matrimonial sexuality (organized by the institution of marriage), if takes place, then relies on its marginal forms.

At the beginning of the 20th century psychoanalysis (with its normalizing tendency) frees sexuality from the connection with heredity and breaks the classical triad "perversion-heredity-degeneration". At the same time, the family is "rehabilitated" as an object of close attention in the context of not only marginal, but also "normal" sexuality.

Foucault depicts the gradual increase of the power of the society (a) over the producing body as a machine (anatomy and politics of the human body) and (b) over the reproducing species body (biopolitics of the population) since the 17th century. The right of authorities to take life is replaced by the right to coerce to it. It is the concentration on life that leads to the formation of a "normalizing society", that is, a society where abnormality is viewed not as a manifestation of monstrosity, but as something potentially concealed in each individual and subject to a purposeful correction (normalization).
The societies of the past, according to Foucault, did not know "scientia sexualis", and the questions about sexuality were answered by "ars erotica". Together with the formation of the science of sexuality, the practice of confession and the instruments of inquiry come to replace the path of discipleship and initiation. In ars erotica "the beautiful" (sublime) is transmitted from the top down - from the teacher to the student, while within the modern practices of "telling the truth" the specialist compels a subject to reveal "the low" (inferior). Proceeding from this, we can conclude that the introduction of sexuality into the economy could not have taken place without recognizing a certain normality of what was previously considered "the low". Henceforth the new discursive field allows and affirms the righteousness of "the low", the right to manifest "the low" and to self-fulfill in it, including public self-realization.

\section{QUESTIONING THE THEORY OF DISCURSIVE CONTROL}

According to the theory of disciplinary control, any fixed identity, including protest identity, can be formed only in the context of a certain power discourse. This means that even a struggle against the power (or, as Butler clarifies, against abuse of it) is carried out by its own rules and is not capable of freeing the subjects of protest identity from its control. However, such a position cannot but meet an objection from the point of view of the logic of political practices. How can one stand for one's own rights, defend one's own interests without consolidation with others on the basis of a common identity? Doesn't such a theory become only "university speculations" and far from the needs of real people?

Butler claims that any consolidating identity operates on the principle of exclusion and thereby itself reproduces the relationship of power. Therefore, there's a need to fight not only for the specific rights, but for establishing an order, in which the struggle for the rights would be unnecessary due to the independence of the individual's status from the inclusion or non-inclusion in certain institutional mechanisms, for example, in the institution of marriage.

Another ambiguous thesis of this theory, which certainly belongs to constructivist social thought, is its main premise, which asserts the subject's non-substantiality. Even the ability of a reflexive thought, according to Butler, is not something overcoming social construction (which could have given the subject a chance to easily transcend the discursive order), since the "I" is always "inside". But can we be sure that the subject and his desire are being totally formed under the influence of discursively determined subjection, and that even naturally biological aspects of them appear socially exclusively through the prism of a particular discourse or certain rules? Rejecting the essentialism, the constructivism of the disciplinary theory, on the one hand, reveals the sociohistorical nature of any regulatory principles and the potential possibility of changing them, but, on the other hand, it places the entire subject in the trap of discursive forms, he ever fails to escape.

The question that we cannot help but ask in this regard: is there a subject in a certain initial form before one's subjection? Suppose that, but, most likely, not as a constant 
(which would mean "naturalization" of the subject) and not even as a function, but not simply as a variable (Butler mentions that "subject" is not equal to "individual", it is "a place for a variable", "structure in its continuous formation"), but as a function of the function, pre-existing the dynamics of the possible values of this variable [14]. The problem is how to derive this function, if not in the categories of a particular discourse?

The theory of discursively-disciplinary power is in no hurry to share the repressive hypothesis, believing it produced within a particular discourse of power and doubting the heuristic significance of the concept of "suppression" because of its uncertainty, preferring the category of "control". However, in spite of this, certain elements of that hypothesis survives the criticism of the theory of disciplinary discourse, and some of them should be mentioned here.

First, describing passionate attachment of a child to his parents, which will be subsequently reproduce itself in adult attachments to submission, Butler develops one of the cornerstones of the concept of repressive social order, proposed by Freud and Reich.

Secondly, the theory of disciplinary power does not exclude the assumption of if not an alternative model (which we will also formulate in terms of the current discourse and the current norm), then at least the fact of a possible alternative (Marcuse also wrote that the social criticism today in a paralyzed state, and it is necessary first to critically transcend, to abstract from the logic of the existing order) [15]. Claiming the non-absoluteness of the norm, the Lacanian Law, Butler makes the first step to its transcendence.

Finally, we should not dismiss the idea of the transforming power of fantasy but necessarily updating it with the requirement to avoid the categories of fixed identities and binary oppositions [16]. Modern utopia ceases to be "a place that is not there" and is searched for distant distances, but becomes a mode of the subjective, struggling for the authenticity of its existence here and now, against a complex and ambiguous reality [17]. The dream is not unfamiliar to the disciplinary theory: in particular, Foucault allows himself to dream of another "economy of bodies and pleasures". Such a fantasy deprives the existing economy of bodies and pleasures, "obsessed" with sexuality, of its immanent status.

\section{CONCLUSION}

Speaking about the absoluteness of the norm Butler disputes Lacan's postulate that symbolic Law is ahistorical (structural in the understanding of K. Levi Strauss, who believed that basic structures are also ahistorical and indifferent to their content). Together with the Law Lacan absolutizes the lack and insufficiency, experienced by the subject and the never-ending conflict between desire and reality. Butler supposes that they are sociogenic and nonabsolute.
According to Foucault, sexuality precedes sexual practices, so real liberation can be sought not in the affirmation or denial of certain practices, but solely in overcoming our enchantment by sexuality itself. The emphasis should be shifted from a focus on sexual desire (which is discursively formed and directed) to attention to the body and its pleasures. This can serve as a basis for opposing the power of sexuality. In what way are the bodily acts and pleasures of the body different from sexuality? The body has the potential to participate in sexuality, however it is sexualized only in specific dispositions caused by particular discourse (for example, when defined as a body of either sex due to existing gender norm). Sexuality is not possible without discursively formed identity, while the body is able to escape from the logic of identities and binary oppositions, as it is, for Butler, neither male or female, but always individual, identical only to itself, and not to some invariant self, but to itself at the current moment.

Non-participation in the mechanisms of power, complete self-elimination from them are impracticable for the subject. However, according to Butler, the discursive signification of the gender practices can be undermined by parodic involvement in them, creating multiple signification, which erodes stable identities. The repetition of identities that Butler talks about is like a Deleuzian simulacrum as a repetition that is always different from the original [18]. This is an identity, which is an essentially infinite list of characteristics, ending with the open formula "and so on". Such an identity Butler calls "identity et cetera" [19]. If we think of individuality not as something that participates in practices but as an effect produced by them, then instead of a generalizing consolidating identity we should produce a lot of local and differentiated strategies that should lead not to the acquisition of specific rights by representatives of a specific identity, but to radical multiplication of democratic practices as such [20].

\section{REFERENCES}

[1] Ph. Tagirov, The Repressive Hypothesis: Natural Sexuality, Suppressed Eros and a Chance of an Alternative?, Proceedings of the International Conference on the Contemporary Education, Social Sciences and Humanities (ICCESSH 2017). Paris, Atlantis Press, 2017 , pp. $56-60$.

[2] M. Foucault, The History of Sexuality. Pantheon Books, New York, 1978 , pp. 15 - 50

[3] J. Butler, The Psychic Life of Power. Stanford University Press, Stanford, 1997, pp. 1 - 30.

[4] L. Bronzino, E. Kurmeleva, "Identity in Contemporary Society: A Gender Perspective" in European Society or European Societies? 9th Conference of the European Sociological Association, 2009, pp. 335 337.

[5] J. Butler, Gender trouble: feminism and the subversion of identity. New York, 1990, pp. vii-xii, 79 -149.

[6] J. Butler, Undoing Gender. New York, 2004, pp. 40-56.

[7] J. Butler, The Psychic Life of Power, pp. 1-30.

[8] Ph. Tagirov, Sexuality and Its Preferences: between Binary and Plural Logic. Proceedings of the International Conference on Contemporary Education, Social Sciences and Humanities (ICCESSH 2016), Paris, Atlantis Press, 2016, pp. 650-656.

[9] J. Butler, The Psychic Life of Power, pp. 106-131. 
[10] M. Foucault, The History of Sexuality, pp. 15-50.

[11] J. Butler, The Psychic Life of Power, pp. 83-106.

[12] M. Foucault, The History of Sexuality, pp. 115-132.

[13] M. Foucault, Abnormal, Lectures at the College de France 1974-1975. Verso, London, New York, 2003, pp. 167-194.

[14] J. Butler, The Psychic Life of Power. Pp. 1-30.

[15] H. Marcuse, One-Dimensional Man. Routledge Classics, London and New York, 2002, pp. xxxix-xlviii.

[16] H. Marcuse, Eros and Civilization. Beacon Paperback, 1974, pp. 140158

[17] S. Rudanovskaya, Possibilities of the Subject in Feminist Utopian Fiction "Woman on the Edge of Time". Proceedings of the 2016 International Conference on Arts, Design and Contemporary Education (ICADCE 2016), Paris, Atlantis Press, 2016, pp. 147-152.

[18] G. Deleuze, Difference and Repetition. Columbia University Press, New York, 1994.

[19] J. Butler, Gender trouble: feminism and the subversion of identity, pp. $142-150$.

[20] J. Butler, Undoing Gender, pp. 40-56. 